\title{
NEAR FAULT VELOCITY PULSE ESTIMATION: THE CEPHALONIA FEB. 3, 2014 EARTHQUAKE (M6.0)
}

\author{
Theodoulidis N. ${ }^{1}$ and Grendas I., \\ ${ }^{1}$ Institute of Engineering Seismology and Earthquake Engineering, Terma Dassiliou, Pylaia, \\ 55535, Thessaloniki, Greece, ntheo@itsak.gr \\ ${ }^{2}$ Aristotle University of Thessaloniki, Department of Geology, 54124, Thessaloniki, Greece
}

\begin{abstract}
Near fault ground motions can be significantly different than those further away from the seismic source. Within the near fault zone ground motions are drastically influenced by the rupture mechanism, the direction of rupture propagation relative to the site and possible permanent displacement related to the fault slip. During the past two decades several sophisticated theoretical or/and empirical methods have been proposed to simulate near fault motion requiring input parameters that hardly can be provided with accuracy, leading thus to extended parametric studies and uncertainties. In this paper, a simple but effective analytical model that mathematically represents near fault ground motions (Mavroeidis and Papageorgiou, 2003) is applied and tested in the case of Cephalonia, Feb. 3, 2014 earthquake (M6.0). Its validity and reliability are examined and an effort to distinguish source and possible site effects is attempted for the town of Lixouri (LXR1 accelerograph) where the highest damage levels was observed.
\end{abstract}

Keywords: near fault, velocity pulse, strong motion, site effects, Cephalonia.

\section{Пврі́ $\eta \psi \eta$}

H

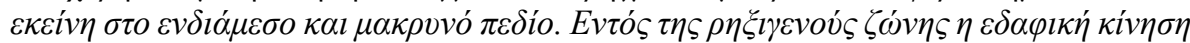

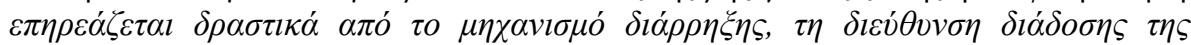

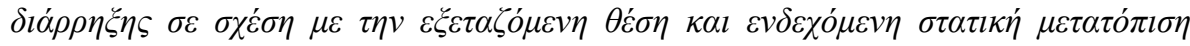

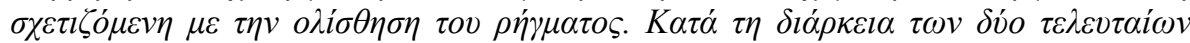

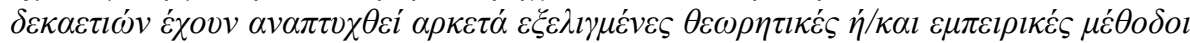

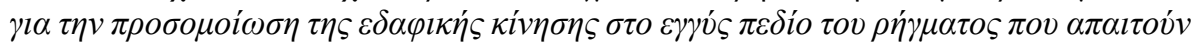

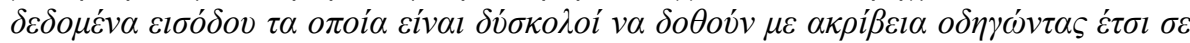

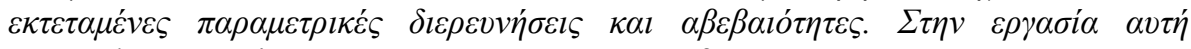

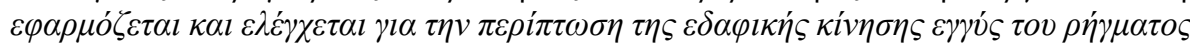

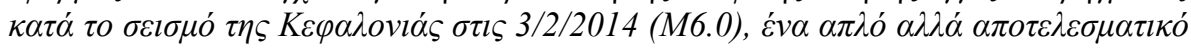

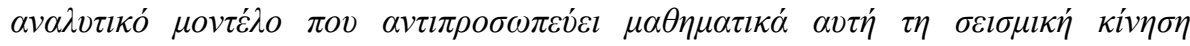

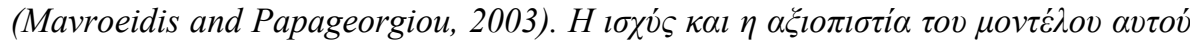

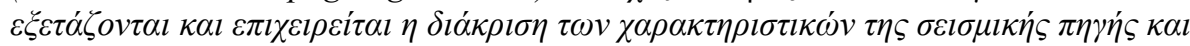

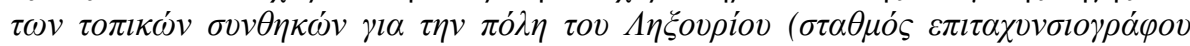

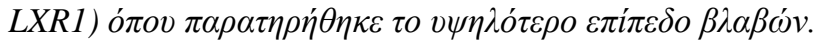

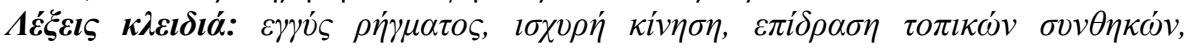

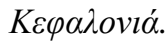




\section{Introduction}

In January 26 and February 3 of 2014, two moderate magnitude earthquakes M6.1 and M6.0, respectively, occurred in Cephalonia Island (Greece). Both shocks were right lateral strike-slip events and occurred on the Cephalonia Transform Fault zone. Strong ground motion was recorded in the near fault by the permanent and temporary accelerometer network of ITSAK, with the highest to date acquired peak ground acceleration in Greece ( $\mathrm{PGA}=0.77 \mathrm{~g}$ at Chavriata: $\mathrm{CHV} 1$ station) (Theodoulidis et al., 2015). High level of damage on buildings and infrastructure was mainly observed at the Paliki peninsula, western part of the Cephalonia island, where the causative fault is located (Fig. 1).

Near fault ground motion involves particular features from engineering point of view, the most important of which is the velocity pulse (Bouchon, 1979; Somerville, 1998; Rodriguez-Marek, 2000; Stewart et al., 2001; Somerville, 2003; Mavroeidis and Papageorgiou, 2003). The severe implication of such velocity pulses on the performance of long period structures was recognized by the majority of engineers only after the 1994 Northridge, California, earthquake and they started considering methods to incorporate the near fault effects in seismic codes. Near fault recordings are sparse worldwide though during the last 20 years relative database was gradually enriched. Such a database was compiled by Mavroeidis and Papageorgiou (2003) and served as a basis for the calibration of their proposed analytical model.

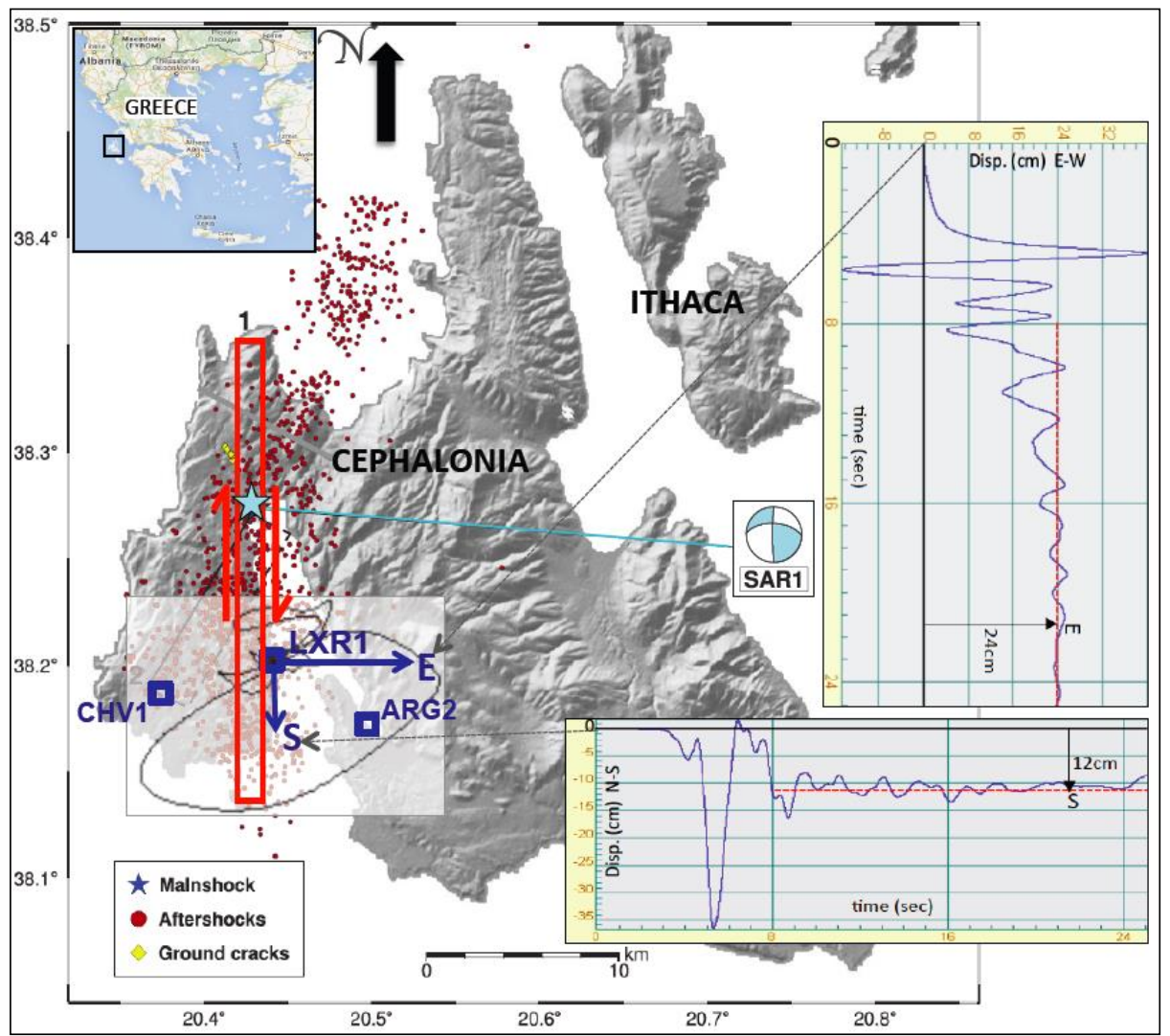

Figure 1 - Fault projection -red rectangle- of the Feb. 3, 2014 earthquake (M6.0) (modified

from Boncori et al., 2015) along with recorded ground displacement in both horizontal components of the LXR1 accelerograph. Permanent displacement at LXR1 in E-W and N-S directions is shown (blue arrows). Particle motion of displacement at the LXR1 station is also shown. 
In the present work near fault strong ground motion characteristics are investigated in order to understand and -if possible- to distinguish the source and site effects, especially within the severely stricken area around Lixouri town (LXR1 station). For this purpose an analytical model proposed by Mavroeidis and Papageorgiou (2003), hereafter MP03, representative of near fault strong ground motion is used for the prediction of the respective velocity pulse. This model is applied at three near fault stations and its results are compared with observed data of the Feb. 3, 2014 earthquake in Cephalonia island, Greece. Apart from near fault source effects, possible influence of site effects is also investigated and discussed.

\section{Data and Model Used}

In this paper a simple approach is proposed to blindly predict near fault ground motion, with emphasis in the characteristic velocity pulse, given the causative fault geometry and its corresponding magnitude. To this purpose an analytical model based on the mathematical representation of the near fault ground motion by Mavroeidis and Papageorgiou (2003) [hereafter: MP03] is used. Its mathematical representation constitutes a simple analytical model for near fault pulses, which uses as parameters the pulse duration (period) $\mathbf{T}_{\mathbf{0}}(\mathrm{sec})$, the pulse amplitude $\mathbf{A}$ $(\mathrm{cm} / \mathrm{sec})$, the signal phase $\mathbf{v}_{\mathbf{o}}$ (degrees) and the oscillatory character of the signal $\gamma$ (i.e. for small $\gamma$ the signal approaches a delta like pulse, as $\gamma$ increases the number of zero crossing increases). There is also the parameter $\mathbf{t}_{\mathbf{o}}$, which specifies the epoch of the envelope's peak, without affecting the produced pulse. This parameter provides an extra flexibility to the signal, allowing its translation along the time axis. The $t_{0}$ parameter, takes suitable values, so that the synthetic pulses is coincident in time with the real pulses, so as to be comparable. In this work we study the form of the synthetic pulse and not its generating time that relates to the origin time of the earthquake, since the $t_{o}$ parameter is not examined.

The normalized velocity signal of the MP03 is expressed by the equation:

$$
\bar{v}(\bar{t})=\frac{\bar{v}(\bar{t})}{A}\left\{\begin{array}{c}
\frac{1}{2}\left[1+\cos \left(\frac{\bar{t}}{\gamma}\right)\right] \cos (\bar{t}+v) \\
0, \text { otherwise }
\end{array},-\pi \gamma \leq \bar{t} \leq \pi \gamma \text { with } \gamma<1\right.
$$

with $\bar{t}=2 \pi f_{p}\left(t-t_{0}\right)$

According to MP03, assuming that the duration of the pulse is independent of the source-station distance for stations located within $\approx 10 \mathrm{~km}$ from the causative fault, velocity pulse period $\mathrm{T}_{0}$ is strongly correlated with the moment magnitude, $\mathrm{M}_{\mathrm{w}}$, through the following relation:

$$
T_{0}=-2.9+0.5 M_{w}
$$

That is, given the earthquake magnitude of the causative fault, one can determine the expected near fault pulse duration, $\mathrm{T}_{0}$.

Regarding to the independent variable A (in $\mathrm{cm} / \mathrm{s}$ ), which controls the pulse amplitude and the PGV (in $\mathrm{cm} / \mathrm{s}$ ), it can be directly related to the observed peak ground velocity given the fact that in MP03 [Table 1 and 3] they are both provided. Based on the exported A values and the corresponding PGV data of specific earthquakes MP03 [Table 1], we correlated these two variables by a linear regression analysis with the following relation (Fig. 2):

$$
P G V=1.15 A+2.44
$$

That is, given the average PGV, one can determine the corresponding average near fault pulse amplitude, A. 


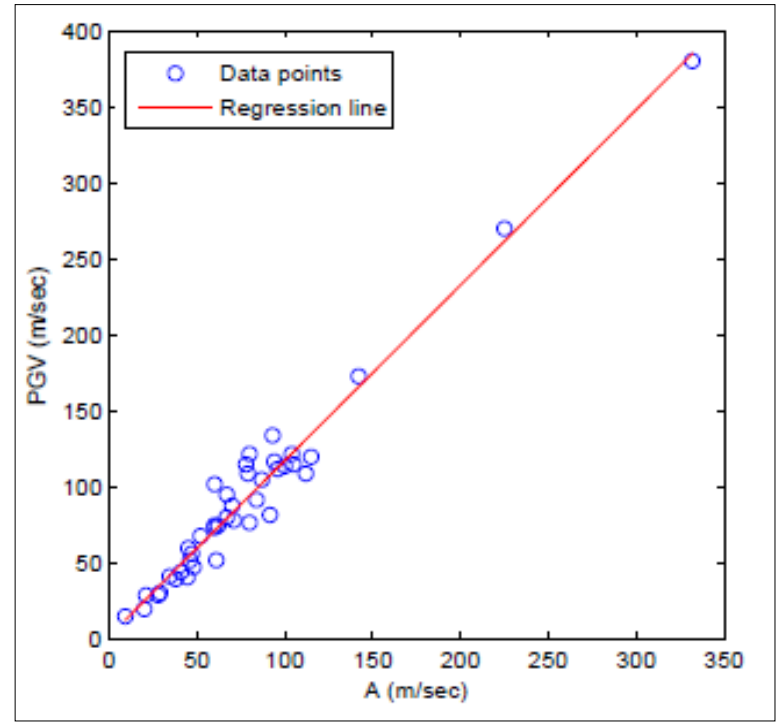

Figure 2 - Correlation between pulse amplitude A and observed peak ground velocity, based on data provided in MP03.

For the determination of PGV one of the most recent relative predictive models, namely, the NGA2 relationship proposed by Boore et al. (2014) was chosen. This model is expressed by the equation:

$\ln P G V=F_{E}\left(M_{w}\right.$, mech $)+F_{p}\left(R_{J B}, M_{w}\right.$, region $)+F_{S}\left(V_{S 30}, R_{J B}, M_{w}\right.$, region, $\left.z_{1}\right)+\varepsilon_{n} \sigma\left(M_{w}, R_{J B}, V_{S 30}\right)$

where the natural logarithm of the peak ground velocity, $\ln P G V$, depends on the source function $\left(\mathrm{F}_{\mathrm{E}}\right)$, the path function $\left(\mathrm{F}_{\mathrm{P}}\right)$ and site effect function $\left(\mathrm{F}_{\mathrm{S}}\right) . \sigma$ is the total standard deviation of the model and $\varepsilon_{\mathrm{n}}$ is the fractional number of standard deviations for a single predicted value of $\ln (\mathrm{PGV})$ away from the mean (for details see Boore et al., 2014). The predictive relation (4) was chosen among numerous published worldwide because it is based on the most extensive and updated strong motion database, including almost all worldwide available and reliable near fault strong motion recordings.

The independent variables of the relation (4) are, the fault type ('mech') ( 0 for "unspecified", 1 for SS-“strike slip", 2 for NS-"normal" and 3 for RS-"thrust \& reverse"), the moment magnitude $\left(M_{w}\right)$, the Joyner-Boore distance $\left(\mathrm{R}_{\mathrm{JB}}\right.$ in $\mathrm{km}$; defined as the closest distance to the surface projection of the fault, which is approximately equal to the epicentral distance for events of $M_{w}<6$ ), the parameter 'region', which is related to the regional variations in crustal damping and is 0 if no regional correction is to be made, 1 for California, New Zealand and Taiwan (indicated as "average Q", 2 for Italy and Japan (indicated as "low Q") and 3 for China and Turkey (indicated as "high Q"). Regarding the site parameters, the average shear-wave velocity $\mathrm{V}_{\mathrm{S} 30}$ (in $\mathrm{m} / \mathrm{s}$ ) and the basin depth $\mathrm{Z}_{1}$ (in $\mathrm{Km}$ ), up to which shear wave velocity reaches the horizon of $1.0 \mathrm{Km} / \mathrm{s}$. In case that $Z_{1}$ is unknown, the function $F_{\delta Z 1}$, that is a component function of the $F_{S}$ function, is zero $\left(F_{\delta Z 1}=0\right)$ and it is not taken into account in the estimation of PGV. $\varepsilon$ is the fractional number of standard deviations of a singl e predicted value of $\ln P G V$ away from the mean and $\sigma$ is the total standard deviation of the model. That is, given the aforementioned parameters, one can determine the corresponding PGV. Hence, considering all the above, the parameters which could determine the form of the synthetic pulse based on the analytical model of MP03, are the 'mech', $\mathbf{M}_{\mathbf{w}}, \mathbf{R}_{\mathbf{J B}}$, 'region', $\mathbf{V}_{\mathbf{s 3 0}}, \mathbf{Z}_{\mathbf{1}}, \mathbf{v}$ and $\gamma$. In order to test the proposed in this work approach, recorded ground velocities at the ARG2, CHV1 and LXR1 are used (Theodoulidis et al., 2015). The extracted results concerning the pulse simulati on process mentioned above were obtained by using the software platform of MATLAB (2012). 


\section{Results}

\subsection{Seismic Source Effects}

In this study, comparison of the synthetic pulses in relation to the real maximum ones for the average PGV horizontal component, is done. For each one of the examined stations, the same independent parameters 'mech', $\mathrm{M}_{\mathrm{w}}, \mathrm{R}_{\mathrm{JB}}$, 'region', $\mathrm{V}_{\mathrm{S} 30}, \mathrm{Z}_{1}$, were used while the parameters $v$ and $\gamma$ were given a range of values. The values of the independent parameters stem from the Cephalonia, Feb. 3, 2014 earthquake, as well as from information of the Lixouri, Chavriata and Argostoli stations; LXR1, CHV1 and ARG2, respectively. According to the MP03 study, the values of $\gamma$ must be greater than 1 and up to a maximum 3. For the simulations three representative values within this range, 1.5, 2 and 2.5 are used. Regarding the $\mathrm{v}$ parameter, the simulations were performed for selected discrete values of $v=0^{\circ}, 90^{\circ}, 180^{\circ}$, and $270^{\circ}$, because the rest possible pulses are included within their range. It should be noted, that the simulations performed referred to average PGV values, since standard deviations $\sigma$ is not taken into account $\left(\varepsilon_{\mathrm{n}}=0\right)$.

The simulations performed refer to the Cephalonia, Feb. 3, 2015 earthquake, in near fault stations LXR1, CHV1, ARG2, as mentioned above. Therefore the parameters 'mech' and 'region' which depend only on the source characteristics, maintain their values stable. The earthquake and consequently the simulations concern to a fault, characterized by a right-lateral mechanism with small reverse component (Boncori et al., 2015; among others) close to the well-defined Cephalonia transform fault of (CTF) (Scordilis et al., 1985; Louvari et al., 1999). Hence the parameter 'mech' is taken equal to 1, for SS - "strike slip" faults and the parameter 'region' is taken equal to 2 because high seismic attenuation (low Q factor) in Greece (Hatzidimitriou et al., 1993) matches better with the attenuation regime in Italy and Japan. Magnitude of the mainshock is equal to 6.0 and the parameters $\mathrm{R}_{\mathrm{JB}}$ and $\mathrm{Vs}_{30}$, are station dependent. According to Boncori et al. (2015) their preferred seismic fault model and its surface projection is the one shown in Fig. 1, as red rectangle, that we adopted in our study. The JoynerBoore distance, $\mathrm{R}_{\mathrm{JB}}$, is $0.5 \mathrm{~km}, 4.5 \mathrm{~km}$ and $5.5 \mathrm{~km}$, for the LXR1, CHV1 and ARG2 stations, respectively. The $\mathrm{Vs}_{30}$ values are $480 \mathrm{~m} / \mathrm{s}, 480 \mathrm{~m} / \mathrm{s}$ and $440 \mathrm{~m} / \mathrm{s}$, for the LXR1, CHV1 and ARG2 stations, respectively (Theodoulidis et al., 2015). Concerning the ARG2 station an alternative value of $\mathrm{V}_{\mathrm{S} 30}$ equal to $750 \mathrm{~m} / \mathrm{s}$ was also considered based on the observed $\mathrm{V}_{\mathrm{sz}}$ values for depth greater than $10 \mathrm{~m}$ at the station. Basin depth $\mathrm{Z}_{1}$ in all three stations is unknown and hence $\mathrm{F}_{\delta \mathrm{Zl}}=0$ was taken. The values used for near fault pulses in this study, are presented in Table 1.

Table 1 - The values which are used in this paper about the simulation production and corresponding to the Cephalonia, Feb. 3, 2014 earthquake (M6.0).

\begin{tabular}{|c|c|c|c|c|c|c|}
\hline $\begin{array}{c}\text { Station Code/ } \\
\text { Model } \\
\text { Parameters }\end{array}$ & \multicolumn{2}{|c|}{ LXR1 } & \multicolumn{2}{|c|}{ CHV1 } & \multicolumn{2}{|c|}{ ARG2 } \\
\hline $\mathrm{R}_{\mathrm{JB}}(\mathrm{km})$ & \multicolumn{2}{|l|}{0.5} & \multicolumn{2}{|l|}{4.5} & \multicolumn{2}{|l|}{5.5} \\
\hline $\mathrm{V}_{\mathrm{S} 30}(\mathrm{~m} / \mathrm{sec})$ & \multicolumn{2}{|l|}{480} & \multicolumn{2}{|l|}{480} & 440 & 750 \\
\hline$v($ deg. $)$ & \multicolumn{2}{|c|}{$0,90,180,270$} & \multicolumn{2}{|c|}{$0,90,180,270$} & \multicolumn{2}{|c|}{$0,90,180,270$} \\
\hline$\gamma$ & $\begin{array}{l}1.5, \\
2.0,2.5\end{array}$ & $\begin{array}{l}1.5,2.0, \\
2.5\end{array}$ & $\begin{array}{l}1.5,2.0, \\
2.5\end{array}$ & $1.5,2.0,2.5$ & $\begin{array}{l}1.5,2.0, \\
2.5\end{array}$ & $\begin{array}{l}1.5,2.0, \\
2.5\end{array}$ \\
\hline$\varepsilon_{\mathrm{n}}$ & 0 & 0 & 0 & 0 & 0 & 0 \\
\hline
\end{tabular}

For the station in Chavriata (CHV1) which is $4.5 \mathrm{~km}$ away from the fault projection, Fig. 3 clearly shows that the real maximum pulse recorded in N-S component, is in good agreement with the synthetic pulses. Most specifically, the synthetic pulse with period $T_{0}=1.25 \mathrm{sec}$, for values $v=0^{\circ}, \gamma=2$ and amplitude $\mathrm{A}=67 \mathrm{~cm} / \mathrm{sec}$ is the best fit with the observed pulse. In this case, both period pulse and amplitude are comparable. The main difference between synthetic and observed data is the high frequency content, $\sim 3 \mathrm{~Hz}$, of the latter that may be due to local site effects. 


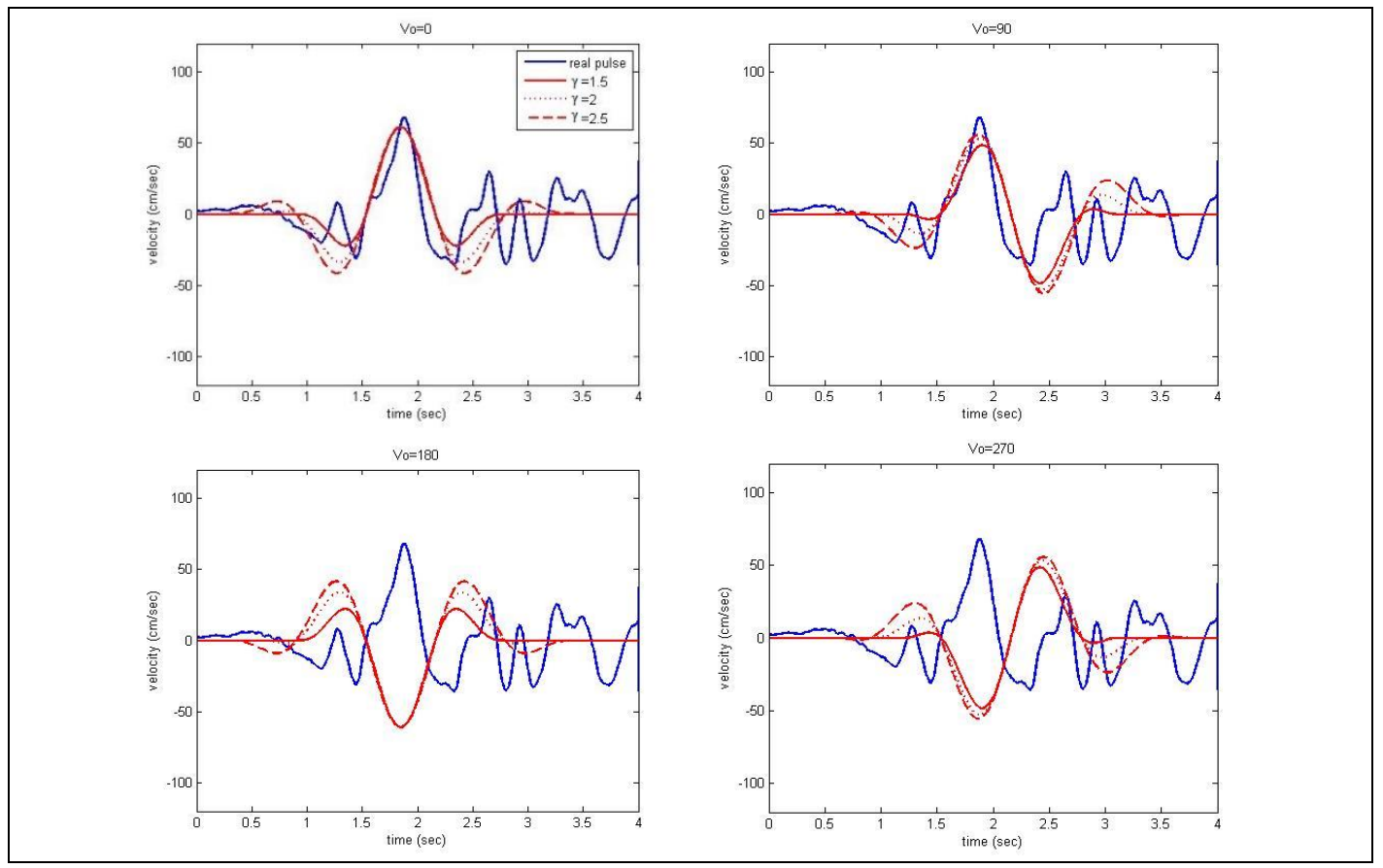

Figure 3 - Velocity pulse simulations (red lines) in comparison with the maximum recorded velocity pulse at the CHV1, in N-S horizontal component (blue line), of the Cephalonia, Feb. 3, 2014 earthquake (M6.0).

For the station in Argostoli (ARG2) which is $5.5 \mathrm{~km}$ away from the fault projection, it is clearly shown that the observed maximum pulse recorded in $\mathrm{N}-\mathrm{S}$ component, is in good agreement with the synthetic pulses, mainly with the synthetic pulse with period $T_{0}=1.25 \mathrm{sec}$, for values $v=180^{\circ}, \gamma=2$ and amplitude $\mathrm{A}=-35.5 \mathrm{~cm} / \mathrm{sec}$, but for $\mathrm{Vs}_{30}=750 \mathrm{~m} / \mathrm{sec}$ (Fig. 4). It is evident that in order to better simulate the velocity pulse at ARG2 station higher shear wave velocity, $\mathrm{Vs}_{30}$, is required.

Synthetic velocity pulse at Lixouri station (LXR1), which is almost on the surface projection of the activated fault with $\mathrm{R}_{\mathrm{JB}}=0.5 \mathrm{~km}$, does not present satisfactory overlapping with the observed maximum velocity pulse which was recorded in E-W component (Fig. 5). The best fit is achieved for values $v=180^{\circ}$ and $\gamma=2$ where synthetic pulse satisfactorily approaches the inverted "bell" shape of the observed pulse. The velocity pulse of the observed data shows a period $T_{0}=1.48 \mathrm{sec}$ and pulse amplitude $A$ is $-118 \mathrm{~cm} / \mathrm{sec}$, while the synthetic a period $T_{0}=1.25 \mathrm{sec}$ and amplitude $\mathrm{PGV}=-81$ $\mathrm{cm} / \mathrm{sec}$. This remarkable disagreement between synthetics and observed data both in amplitude and pulse period may be due to local site effects and deserves further investigation. 


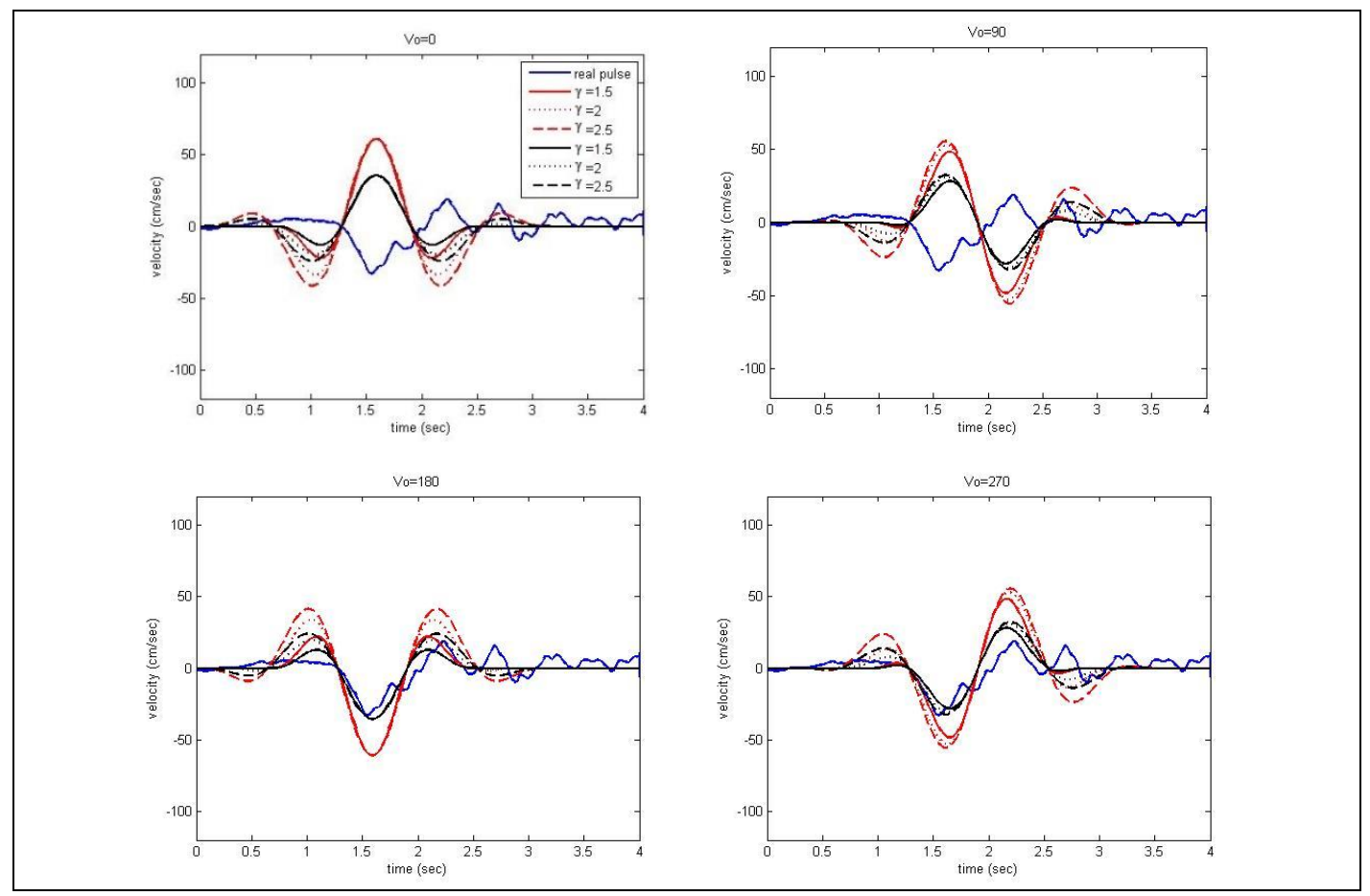

Figure 4 - Velocity pulse simulations $\left(V_{S 30}=440 \mathrm{~m} / \mathrm{s}\right.$ in red lines; $V_{S 30}=750 \mathrm{~m} / \mathrm{s}$ in black lines $)$ in comparison with the maximum recorded velocity pulse at the ARG2, in N-S horizontal component (blue line), of the Cephalonia, Feb. 3, 2014 earthquake (M6.0).

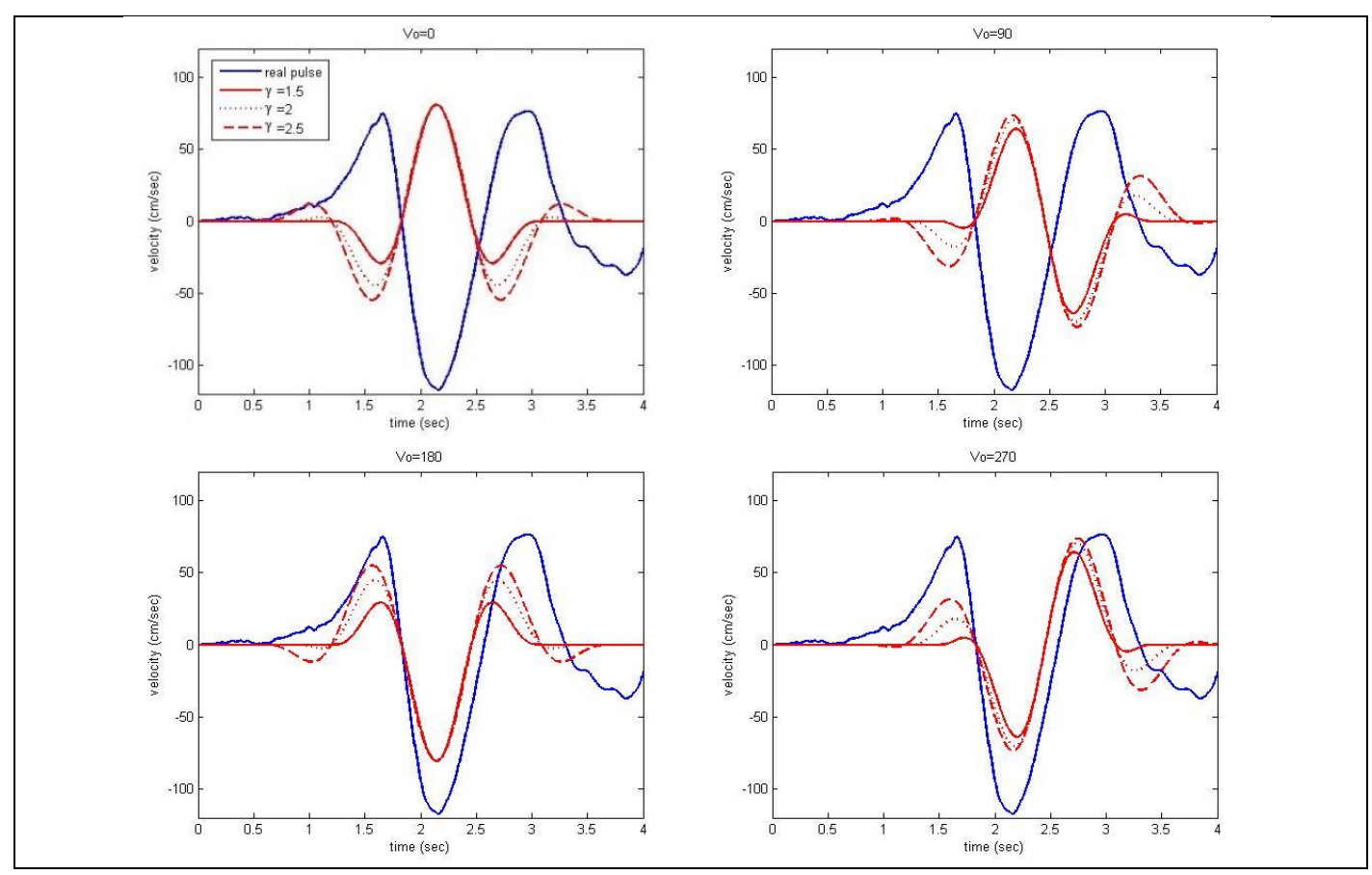

Figure 5 - Velocity pulse simulations (red lines) in comparison with the maximum recorded velocity pulse at the LXR1, in E-W horizontal component (blue line), of the Cephalonia, Feb. 3, 2014 earthquake (M6.0). 


\subsection{Site effects at LXR1 station}

The Lixouri station (LXR1) was almost on the fault projection and according to source characteristics directivity effect was expected to be very important (Fig. 1). According to Boncori et al. (2015), permanent displacement was observed at the Paliki peninsula. More specifically, based on SAR measurements, they observed a clear southeast coseismic displacement of the southeastern part of the Paliki peninsula where Lixouri town is situated. In order to investigate such a phenomenon based on recorded acceleration time history at LXR1 station, uncorrected displacement time history for both horizontal components was calculated (Fig.1). The broadband accelerometer $(\mathrm{To}=20 \mathrm{sec})$ coupled with high resolution digitizer (24bits) allows for permanent displacement detection. In the N-S fault parallel component a permanent displacement of about $12 \mathrm{~cm}$ is observed, in good agreement with that estimated, around $10 \mathrm{~cm}$, from the SAR measurements. In the E-W fault normal component a permanent displacement of about $24 \mathrm{~cm}$ is also evident, the so-called 'fling step' usually observed close to the causative fault. Although in E-W component there is present coseismic slip it is much lower than $24 \mathrm{~cm}$. This is an indication that apart from the source properties there may be a local factor that strongly affected the permanent ground displacement at LXR1 station in the E$\mathrm{W}$ direction. In addition, particle motion of ground displacement shows a preferable $\mathrm{E}-\mathrm{W}$ direction while the larger ellipsis of the particle motion is shifted to southeast of Lixouri (Fig. 1).

In order to investigate influence of strong ground motion on the Horizontal to Vertical (H/V) spectral ratio (Nakamura, 1989; Lermo and Chavez-Garcia, 1994; Theodoulidis and Bard, 1995; SESAME Project, 2004; among others) a 5sec window including mainly the S-wave part of the accelerogram was used. Using the 'geopsy' software (www.geopsy.org) a clear H/V peak around indicates a fundamental frequency fo= $0.78 \mathrm{~Hz}$ with a corresponding amplitude 7.5 has been identified (Fig. 6a). Using the low amplitude acceleration time history, that is the part of motion beyond S-weaves, a fundamental frequency fo $=1.7 \mathrm{~Hz}$ with a corresponding amplitude $\sim 5$ is observed (Fig. 6b). A shift of the fundamental frequency towards lower frequency is clear when ground motion amplitude is increased at LXR 1 station. The fundamental period, $\mathrm{To}=1 / \mathrm{fo} \approx 1.3 \mathrm{sec}$, of the strong motion $\mathrm{S}$-wave window is close to the period pulse, that varies between $1.25 \mathrm{sec}$ and $1.48 \mathrm{sec}$ for the synthetic and observed data, respectively.

(a)
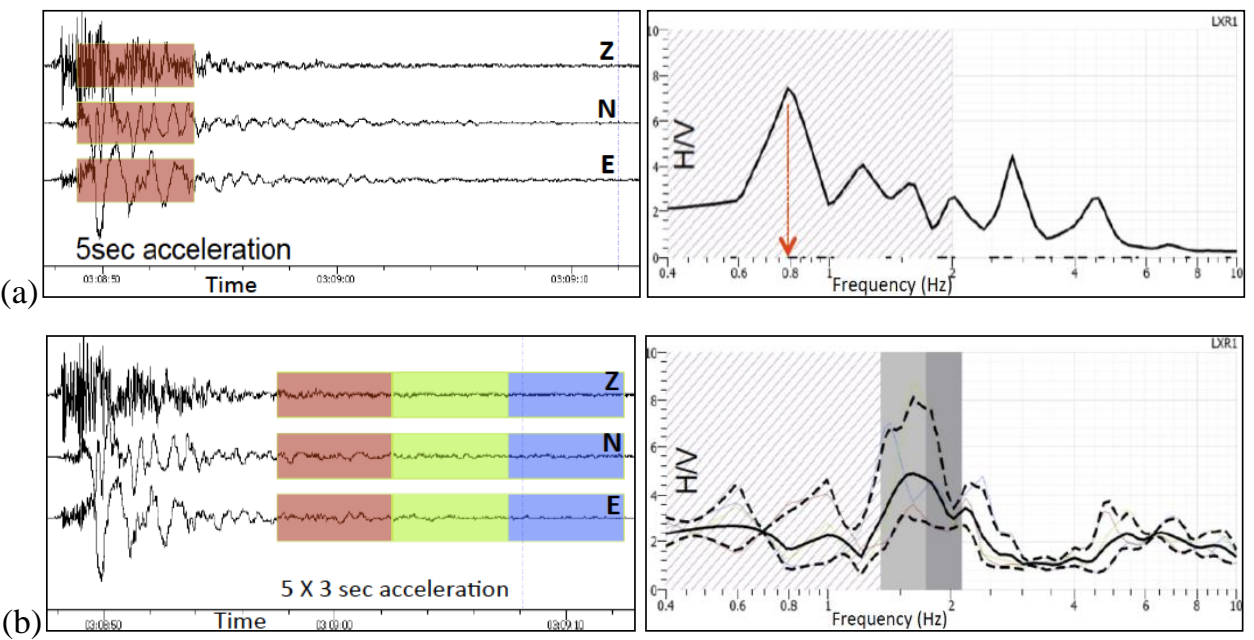

Figure 6 - Horizontal to Vertical spectral ratio at the LXR1 station: (a) using the most energetic part of the acceleration time history and (b) the part beyond the $S$-waves.

\section{Discussion and Conclusions}

In this work an effort to simulate the characteristic near fault velocity pulse of the Cephalonia Feb. 3, 2014 earthquake, is attempted. For this purpose a simple analytical model (Mavroeidis and 
Papageorgiou, 2003) in combination with a recently proposed empirical predictive model of peak ground velocity (Boore et al., 2014) are adopted. The proposed approach is applied to three near fault stations (ARG2, CHV1 and LXR1) where high values of peak ground velocities were recorded.

Comparison of the synthetic near fault velocity pulses with the observed ones showed satisfactory agreement in terms of amplitude and period of the pulse for all three stations. This fact encourages use of the proposed in this paper approach in order to blindly predict near fault ground velocity pulses, responsible for high level damage especially on long period constructions.

However, for the LXR1 station a $15 \%$ increase of the recorded period pulse and $40 \%$ of its amplitude, with respect to the synthetic, one is observed. In addition, from the H/V spectral ratio analyses it seems that fundamental frequency of the surface layers overlain the station drastically changes from high to low amplitude ground motion. Most probably, the representative fundamental frequency of the site is obscured by the source effects (e.g. rupture directivity, fling step) that are intense in the near fault zone. This assumption is further supported by the fact that aftershocks' H/V spectral ratio analyses for the LXR1 station, using low amplitude ground motion recordings, with PGA $<0.05 \mathrm{~g}$, showed a fundamental frequency $1.5 \mathrm{~Hz}<$ fo $<2.0 \mathrm{~Hz}$ (Theodoulidis N., pers. communication, 2015). However, further theoretical investigation, especially in local soil behaviour, is needed (e.g. possible non-linearity) in order to better understand and constrain observed ground motion of the Cephalonia, Feb. 3, 2014 earthquake at the LXR1 station.

\section{Acknowledgments}

This work has been funded by the NERA-EC and E2VP2-CEA projects.

\section{References}

Boncori, J.P.M., Papoutsis, I., Pezzo, C., T., Atzori, S., Ganas, A., Karastathis, V., Salvias, S., Kontoes, C. and Antonioli, A., 2015. The February 2014 Cephalonia Earthquake (Greece): 3D Deformation Field and Source Modeling from Multiple SAR Techniques, Seismol. Res. Lett., 86-1, 124-137.

Boore, D., Stewart, J., Seyhan, E. and Atkinson, G., 2014. NGA - West2 Equations for Predicting PGA, PGV, and 5\% Damped PSA for Shallow crustal Earthquakes, Earthquake Spectra, 30, 10571085.

Bouchon, M., 1979. Predictability of ground displacement and velocity near an earthquake fault: An example-The Parkfield earthquake of 1966, J. Geophys. Res., 84, 6149-6156.

Geopsy software, www.geopsy.org.

Hatzidimitriou, P., Papazachos, C., Kiratzi, A. and Theodulidis, N., 1993. Estimation of attenuation structure and local earthquake magnitude based on acceleration records in Greece, Tectonophysics, 217, 243-253.

Lermo, J. and Chavez-Garcia, F.J., 1994. Site effect evaluation at Mexico City: dominant period and relative amplification from strong motion and microtremor records, Soil Dyn. \& Earthq. Eng., 13, 413-23.

Louvari, E., Kiratzi, A. and Papazachos, B.C., 1999. The Cephalonia Transform Fault and its extension to western Lefkada Island (Greece), Tectonophysics, 308, 223-236.

Mavroeidis, G. and Papageorgiou, A., 2003. A Mathematical Representation of Near- Fault Ground Motions, Bull. Seismol. Soc. Am., 93, 1099-1131.

MATLAB and Statistics Toolbox Release v8.0.0, 2012. The MathWorks, Inc., Natick, Massachusetts United States.

Nakamura, Y., 1989. A method for dynamic characteristics estimation of subsurface using microtre mor on the ground surface, QR Railway Tech. Res. Inst., 30, 25-33.

Rodriguez-Marek, A., 2000. Near fault seismic site response, PhD Thesis, Civil Engin., University of California, Berkeley, 451 pp. 
SESAME Project, 2004. Deliverable D23.12: Guidelines for the implementation of the H/V spectral ratio technique on ambient vibrations measurements, processing and interpretation, available from the web site- http://sesame-fp5.obs.ujf-grenoble.fr/Papers/HV_User_Guidelines.pdf.

Theodoulidis, N. and Bard, P.-Y., 1995. Horizontal to vertical spectral ratio and geological conditions: an analysis of strong motion data from Greece and Taiwan (SMART-1), Soil Dyn. \& Earthq. Eng., 14, 177-197.

Theodoulidis, N., Karakostas, C., Lekidis, V., Makra, K., Margaris, B., Morfidis, K., Papaioannou, C., Rovithis, G., Salonikios, T. and Savvaidis, A., 2016. The Cephalonia, Greece, Jauary 26 (M6.1) and February 3, 2014 (M6.0) earthquakes: Near fault ground motion and effects on soil \& structures, Bull. Europ. Earthq. Eng., 14, 1-38.

Scordilis, E.M., Karakaisis, G.F., Karakostas, B.G., Panagiotopoulos, D.G., Comninakis, P.E. and Papazachos, B.C., 1985. Evidence for transform faulting in the Ionian Sea. The Cephalonia island earthquake sequence of 1983, Pure Appl. Geophys, 123, 388-397.

Somerville, P., 2003. Magnitude scaling of the near fault rupture directivity pulse, Physics Earth \& Planet. Int., 137, 201-212. 